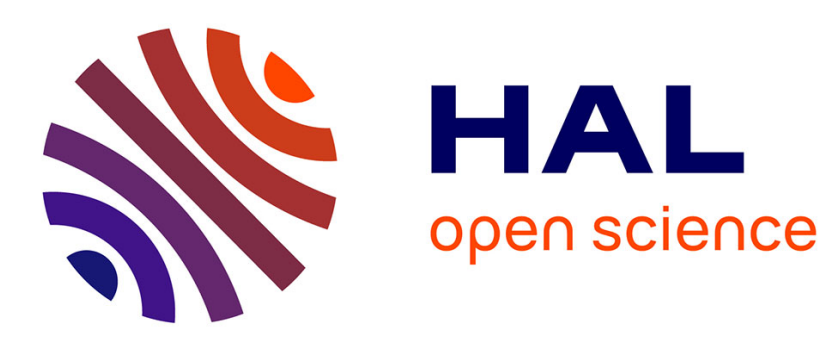

\title{
Functional and residual capital values as criteria for water pipe renewal
}

\author{
A. Nafi, Y. Tlili
}

\section{To cite this version:}

A. Nafi, Y. Tlili. Functional and residual capital values as criteria for water pipe renewal. Structure and Infrastructure Engineering, 2015, 11 (2), pp.194-205. 10.1080/15732479.2013.862728 . hal01357337

\section{HAL Id: hal-01357337 \\ https://hal.science/hal-01357337}

Submitted on 31 Aug 2016

HAL is a multi-disciplinary open access archive for the deposit and dissemination of scientific research documents, whether they are published or not. The documents may come from teaching and research institutions in France or abroad, or from public or private research centers.
L'archive ouverte pluridisciplinaire HAL, est destinée au dépôt et à la diffusion de documents scientifiques de niveau recherche, publiés ou non, émanant des établissements d'enseignement et de recherche français ou étrangers, des laboratoires publics ou privés. 


\title{
Functional and residual capital values as criteria for water pipe renewal
}

\author{
Amir NAFI ${ }^{*}$ and Youssef TLILI**
}

* Joint Research Unit in Water and Environmental Territory Management, Irstea-Engees, 1 Quai Koch 67070, Strasbourg, France (E-mail: amir.nafi@engees.unistra.fr).

** Technical University of Bari, via E. Orabona 4, 70125 Bari, Italy (E-mail: youssef.tlili@engees.unistra.fr).

\begin{abstract}
Water pipes are considered as tangible assets designed to provide a level of service throughout an expected lifetime. The asset can be characterised by two types of values: capital or accounting value and functional value. The capital value of assets depreciates according to a specific rate per time period. The depreciation is assessed by the annual amortisation of the capital asset, which constitutes a potential self-budgeting for future renewal. The development in the last 20 years of public sector accounting standards boards (PSASB) dedicated to tangible capital assets (TCA) management has encouraged water and waste water utilities to consider capital depreciation as a decision-making criterion for asset prioritisation. At the same time that the capital depreciates, the asset function deteriorates, but this deterioration is more difficult to assess. In fact, each asset can be evaluated according to a functional value that indicates the capacity of the asset to deliver the designated service at the required level. This value declines during the service life because of the occurrence of unexpected events (failures, breaks, leaks, degradation). The functional deterioration, also referred to as "obsolescence" or "reliability", is still misunderstood for water pipe assets. This study addresses the following questions: How can the functional value be estimated for water systems both at the pipe and network scale? How can the decision-making process for pipe renewal be improved by incorporating specific indicators based on both functional and accounting values? The current research focuses on the definition of an appropriate time-dependent functional value, based on the following hypothesis: the functional value depends on both structural and hydraulic deterioration of the pipe asset, but is partially restored by curative maintenance actions. The calibration of the functional value is mainly based on historical incident data, roughness data and managers' opinions. In order to carry out the decision-making process, the evolution of the functional value is simultaneously analysed with the depreciation of the capital asset value. The implementation of the approach at pipe and network level leads to an assessment of innovative criteria for the purpose of assessing possible renewal policies.
\end{abstract}

Keywords: asset; capital; depreciation; deterioration; functional, network; residual; value; pipe. 


\section{INTRODUCTION}

Water pipes are considered as tangible assets designed to provide services at a certain level over an expected service life. Because the pipe asset is under internal and external pressures, its condition degrades over time and can harm its function. In order to assess this degradation, concepts such as "obsolescence", "depreciation", "deterioration" and "reliability" are used. The common denominator of all of these concepts is their relationship to asset assessment: the extent to which it delivers the function for which it was designed and how it declines over time. The notion of functional value that we suggest is not widespread in the literature; the concept of obsolescence is more frequently used. It generally concerns commodities and electronic products and is commonly used in the industrial environment. The Australian Property Institute, API (2008) defines obsolescence as "a loss in value due to a decrease in the usefulness of property caused by decay, changes in technology, people's behavioural patterns and tastes, or environmental changes. Obsolescence is sometimes classified according to items of outmoded design and functionality, items with structural design unable to meet current code requirements, and factors arising outside the asset, such as changes in user demand".

For Allehaux and Tessier (2002), a property becomes functionally obsolete when it fails to perform its function. (Gomez et al. 2012) discussed the concept of functional obsolescence and highlighted potential causes that are functional, economic, technological, socio-cultural and legal. All of these factors influence the evolution of the asset over time. The concept of functional obsolescence mentioned by (Gomez et al. 2012) seems interesting for us because it concerns the functional value of the asset and its ability to perform its function. The functional obsolescence analysis cannot be separated from the reliability analysis of the asset. Both analyses should be done at the same time because a time-dependent relationship clearly exists between them. On the basis of this observation, the functional obsolescence state can be defined as the state of the asset when it is not able to perform its function any longer, i.e., the asset has become unreliable. The concept of reliability is widely dealt with in the domain of safety systems. It defines the ability of equipment or an asset to perform its function over time. Reliability is a function of time because it measures the right operation of the asset beyond a certain time $t$. When the asset becomes unreliable, it is functionally obsolete. According to the literature, the following types of asset values appear to be relevant: (i) the capital or accounting value that depreciates over time. The estimation of this value is addressed in depth; and (ii) the functional value that indicates how the deterioration of the structural and technical condition can harm the delivery of the designated service of the asset. The functional asset value declines during the service life because of the occurrence of unexpected events (failures, breaks, leaks, increased roughness, etc.). It could be estimated based on its physical and hydraulic deterioration. The estimation of the asset value is based on the measurement of the decline of its usefulness, and not just on its capital value but on its functionality as well.

This article highlights the time-dependent relationship between the asset degradation at the individual and network scale and the degradation of its function, making it possible to develop innovative criteria for the purpose of improving multi-criteria renewal decision making. The current approach involves the use of statistical models for physical deterioration based on censured data. It aims at developing an innovative way to over cross limits concerning the use of survival analysis models and their results (prediction, expected service life) in terms of input for the pipe renewal decision-making process. The current research addresses the issue of asset value assessment, both at the individual and the network levels, and how it decreases over time. It aims at improving the multi-criteria decision-making process for pipe renewal by proposing criteria that combine both technical and accounting aspects. In order to address the issue in question, this article consists of six sections. The introduction defines the most important concepts with regard to the notion of asset value and how our work is positioned in relation to the literature. 
In Section 2, we discuss the possible asset value according to three types of degradation: (i) physical; (ii) hydraulic; and (iii) capital. An assessment function is discussed for each type. Section 3 details the existing methods and approaches for the diagnosis and the estimation of asset degradation. This section also highlights the significant lack of methods that have yet to be identified, and how they can be addressed. Section 4 presents the major improvements to the existing approach and defines an analytical value function at the individual pipe scale. It also discusses the main hypothesis of the proposed assessment approach. Section 5 describes the implementation of the methodology on a real case study. Two types of results are presented: (i) the decrease of asset value for a pipe, considering its functional, hydraulic and residual value; and (ii) a feasible renewal policy obtained with a multi-criteria decision-aid model improved by asset value criteria. Finally, Section 6 discusses the pertinence of the proposed methodology and how it can be improved, particularly in the context of data scarcity.

\section{THE ASSET VALUE: THE CASE OF THE WATER PIPE ASSET}

Decision making for renewal planning of water distribution systems is a sensitive and complex process based on several criteria that include the condition level and its degradation over time. This evolution depends on variables that are often not directly related to the service or the composition of the asset. Factors related to the asset environment such as design, material, construction, climate and loading have a major influence. This makes the monitoring of the reliability of the asset more complicated because of the irregular frequency of failures, which leads to the incapacity of forecasting the asset degradation curve over the time. Most of the time, the asset is not monitored from the time of its installation. Because data are only available on a partial observation window, they are censured, so the lack of data makes decision making very complex and unreliable. Another challenge concerns the assessment of the asset function rendered. This study is based on the hypothesis that a significant correlation exists between the deterioration of the asset and its delivered service. The decrease of rendered services could be caused by the occurrence of breaks, failures, leaks or unwanted events that harm the operation of the system and can lead to temporary of prolonged service interruption. The increase of internal roughness affects the hydraulic capacity of the pipe, requested pressure and demand could not be provided in some cases. Therefore the presence of incrustation due to corrosion or other deposits can lead to a decrease of water quality. These arguments are close to those mentioned by Rajani and Kleiner (2002). In that case, the asset value decreases if the delivery of the service is disturbed or interrupted. In reality, an asset is connected to other assets in the water systems, making it difficult to assess its function independently from other components. The proposed approach investigates how it is possible to assess the degradation of the asset over time and how this degradation can harm its function; the asset value will depend on its condition and its capacity to perform required functions.

It is obvious that the decision-making process for asset renewal is a multi-stage process based on a multi-criteria analysis (Tlili and Nafi 2012, Nafi and Werey 2009, 2010, Le Gauffre et al. 2004, 2008) or a multi-objective approach (Halal et al. 1997; Nafi and Kleiner 2010). Even if interesting approaches exist in the literature, the decision process concerning pipe renewal is still misunderstood. Water utilities are generally constrained by other services such as sewer utilities or roadwork to anticipate the renewal of assets, even if they continue to correctly ensure their function.

To address this situation, this study aims at highlighting innovative criteria for asset value evaluation based on the establishment of a time-dependent relationship between the multiple degradation of the asset and its impact on its function. The criteria chosen should: (i) improve the decision-making process by avoiding the excavation of the pipe asset that still ensures its function, but should be renewed because of other utility constraints; and (ii) offer mitigation criteria for other public utilities in order to limit their pressures on the water utility. Many types of degradations can 
have an impact both on the function rendered and the asset value. It is recommended to develop a better understanding of these potential degradations and to assess them over time. Degradation can be summarised by two concepts: deterioration and depreciation.

This means that the asset value analysis should be performed not only on the physical and structural state, but also on the capital or accounting value of the asset. What makes our approach innovative is that we analyse the condition of the asset from both the technical and economic point of view. The following section focuses on pipe asset analyses. The review of the literature allows identifying three types of degradations for pipe assets that could have an impact on the asset value: the physical or structural state, hydraulics as a function of the deterioration of the carrying capacity, and the capital depreciation.

\section{The functional value and physical deterioration}

Based on the existence of a significant correlation between the decrease of the functional value and the physical deterioration, the absence of deterioration means that the functional value is unchanged. Therefore, the assessment of the functional value is done in a subtractive way: the value declines when the asset physically deteriorates. A way to deal with functional value assessment is to better understand the physical deterioration and how it can be measured over time.

Physical deterioration has been widely dealt with in the literature. An interesting review is presented in Kleiner and Rajani (2001). The authors highlight the main approaches for structural deterioration analysis by distinguishing between those based on statistical models and those based on specific models for a description of the physical deterioration. The first approach is based on the statistical analysis of a set of historical data gathered on an observation window. Data concern endogenous variables (failures, length, roughness, diameter, pipe material) and exogenous variables (soil occupation, soil type, traffic load, temperature). The use of statistical models makes it possible to establish correlations between pipe failures occurrences and significant covariates in order to fit functions for failure prediction or to assess survival functions at the scale of individual pipes or cohorts. Two types of statistical approaches are implemented: regression and parametric survival analysis. Shamir and Howard (1979) used an exponential model for pipe prediction and the model was adapted for economic assessment of renewal policy by Walski and Pelliccia (1982). (Clark et al. 1982) used a linear regression to predict the number of failures. Constantine and Darroch (1993) and (Constantine et al. 1996) investigated a model based on a Poisson process for breakage occurrence. In the same way, other applications have been done based on the Non-Homogenous Poisson Process (NHPP) proposed by Røstum (2000) and Kleiner and Rajani (2001).

The second type of statistical model is based on a reliability approach. It plebiscites the use of survival analysis models by using the proportional hazard model developed by Cox (1972) or an adaptation of it.

Several applications at the individual water pipe scale or at the cohort level have been done (Marks et al. 1985; Andreou et al. 1987, Eisenbeis 1994, Le Gat 1998, 1999). The models used highlight significant covariates for breakage prediction. An interesting observation has been made on some of the applied models about the existence of an accelerated period for the deterioration process, which could lead to a decrease of the function rendered and could help the decision maker to prioritise pipe assets. Another approach, the cohort survival model Herz (1996), based on expert opinion, was dedicated to pipe cohorts. The model makes it possible to fit the survival function for groups of pipes and the appraisal of an expected service life.

Physical deterioration models focus on the behaviour of pipes in terms of internal and external pressures. Deterioration mechanisms are complex and not completely understood. These mechanisms involve three main aspects: (i) pipe characteristics and the quality of installation; (ii) 
internal and external loads due to pipe pressure, traffic or environment; and (iii) material deterioration due to external and internal chemical, bio-chemical and electro-chemical interactions.

Rajani and Kleiner (2001) proposed an interesting review of models dedicated to physical deterioration. Even if these approaches seem relevant, our approach does not deal with the mechanisms of mechanical deterioration but instead explore the way to adapt statistical analysis to describe physical deterioration using the collection of data related to unexpected events.

Most of the cited models and approaches aim at establishing a correlation between observed physical deterioration and covariates in order to predict the cumulative number of breakages on a time window. The results obtained should be used as an input in the decision-making process for pipe renewal, but no clear indication exists about how failure predictions should be used. Part of this question is addressed in the literature by the use of breakage prediction in an economic analysis based on the balance between the discounted total cost of failures and the discounted cost of pipe renewal. When the cost of failure exceeds the cost of renewal, the pipe becomes economically unviable. It is a candidate for renewal even if it ensures its function. The use of this approach may help to identify the pipe candidates for renewal. It also may estimate the optimal economic date of their renewal by combining economic and structural deterioration criteria but it neglects their capacity to deliver their function which can be considered as a shortfall.

Theoretically, if the physical deterioration is not related to the degradation of the delivered function, the pipe can break indefinitely. Therefore, the prediction of future breaks is not sufficient in itself to make decisions concerning the analysed pipe asset. Thus, the observation concerns the survival function performed in the references cited, where the data were generally right-censured which indicates that the analysed asset is still in operation. Even if some pipes are removed, the cause of excavation is not necessarily related to their physical deterioration but to multiple reasons (sewers or roadwork, pavement refection, interventions on other buried infrastructures, urban development, etc.). For all these reasons, it is necessary to link physical deterioration and the degradation of the function ensured by the asset considered to improve the decision-making process.

\section{The functional value and hydraulic deterioration}

The hydraulic deterioration of the pipe asset has an impact on its function and obviously decreases its functional value. Within the scope of this study, the hydraulic deterioration is analysed at the individual pipe level. Concerning hydraulic deterioration, two closely-related concepts are widely treated in the literature: the decrease of hydraulic capacity of the pipe asset and the concept of hydraulic reliability. The decrease of hydraulic capacity is related to the variation of the carrying capacity of the pipe since deterioration of the internal pipe wall causes an increase in roughness or a decrease in the internal diameter that harms its hydraulic operation. Colebrook and White (1937), Hudson (1966) and Sharp and Walski (1988) investigated the increase in roughness and its variation over time for unlined cast iron (CI) pipes. Most applications of these approaches aim at improving hydraulic simulation models of the water network in order to better match its real operation over time by taking the decrease of the carrying capacity of pipes into account. Because the hydraulic system is a connected network, reliability also depends on its topology. The location of pipes and other hydraulic organs have a different influence on the operation of the network, especially when unexpected events occur. Two concepts of reliability are mainly discussed in the literature: topologic reliability and hydraulic reliability. They complete the reliability analysis of each component itself by extending the analysis to all components that belong to a system. The topologic reliability deals with the impact of the occurrence of an unexpected event on the connectivity of the network. It expresses the existence or not of links between the nodes of the network and a source node that continue to supply the connected nodes (Otsfeld et al. 2002, Røstum 2000). According to 
(Xu et al. 1999), hydraulic reliability is assessed by the capacity of the network to deliver the required demand on nodes with a defined minimum pressure level.

Hydraulic reliability depends on both the failures of hydraulic components (pipes, valves, pumps, leakage, bursts) and the decrease of hydraulic capacity that depends on pipe deterioration (increased roughness, corrosion, etc.).

(Wagner et al. 1988) defined two notions in relation to hydraulic reliability: (i) reachability that deals with the probability of a given node (consumer node) to be connected to one or more source nodes; and (ii) the concept of connectivity that estimates the probability that all the nodes of the network are connected to a minimum of one source node. Shamsi (1990) and Quimpo and Shamsi (1991) defined NPR (Node Pair Reliability) as the probability that a given node is connected to a specified source node. Topologic reliability appears to be linked to the research of a path between the network's node and one or more source demands, without considering the hydraulic aspects such as pressure, flows and demand. It is clear that even if possible paths exist, and that the delivery of water is possible, the service level is not necessarily ensured. Todini (2000) indicates the importance of taking the topology of the network into account in the decision-making process by comparing the reliability of a network with mesh and branch topology, for example. The topology of the network is not imposed by the utility manager but depends in most of the time on constraints linked to the location of consumers, roads, natural obstacles and the presence of other networks: gas, sewers and electricity. Todini (2000) defined the concept of resiliency as the capacity of the water distribution network (WDN) to ensure a correct operation when an unexpected event occurs and restricts the impacts. For the author, the WDN should be able to deal with temporary incidents when the degradations are considerable. The reliability of the network therefore depends on its capacity to decrease the impact of the occurrence of failures on its operation. Ormsbee and Kessler (1990) defined redundancy as a measure of the reliability. Möderl and Rauch (2011) proposed an interesting model for vulnerability assessment of water pipes. It is based on the combination of specific performance indicator (PI) calculated from pressure and demand variation due to abnormal condition in one hand, and a spatial risk assessment in other hand. Several reliability (or critical) indices and indicators have been computed based on the relationship between demand and pressure established by (Wagner et al. 1987). Most of these indices compare the delivered volume of water before and after failure occurrence or took the variation of demand and pressure on the hydraulic model into account.

According to the literature review, the hydraulic deterioration seems closer to the concept of hydraulic reliability that can be defined on the basis of the topology of the network than on its operation. It is clear that the hydraulic deterioration can be assessed at the pipe scale (on an individual element of the whole system) or that it can be measured on the whole operating system. In the current work the hydraulic deterioration analysis is used to estimate the functional value at the individual pipe level.

\section{The residual value and capital depreciation}

From an accounting point of view, a water pipe is a tangible asset characterised by a capital or accounting value that is maximal at its installation date and that corresponds to the amount of capital expenditure (CAPEX), also referred to as historical value. The value depreciates over time because of the use of the asset, deterioration and possible obsolescence. The loss of value estimated by the amount of depreciation is theoretically equal to the amount of accounting amortisation over a period of time. This period of time is known as the expected service life or useful life, which corresponds to the desired time period when the pipe asset correctly delivers its function. For pipe assets, the expected service life is generally considered to be between 50 and 70 years. The legislation encourages the asset's owner to amortise tangible assets over an estimated service life period that makes it possible to compensate for the depreciation of the asset value. Even if accounting depreciation practices are not new, they were more commonly used for private 
enterprises in the past and not widely applied for the management of public infrastructures. Water utilities have not been used to amortise network assets or to constitute a reserve for self-budgeting. The practice of depreciation has been developed by the implementation of specific public sector accounting standards boards, (PSASB) (FRS 1999, DGCL, 2004, CICA 2007, IFRS, 2012, AASB 2013) for water and wastewater utilities in several countries.

The PSASB provides recommendations and detail how the asset should be analysed and how accounting should be practiced. They define specific rules and parameters concerning the type of depreciation, its duration (expected service life) and the installation value that should be taken. Graham (2007) described the current practices used in the calculation of depreciation infrastructure assets held by Australian 'not for profit' entities such as local government and water authorities. He defined depreciation as the irreversible reduction of the status of an asset, spread out over a period of time, which is an accounting recognition of a reduction in the value of the asset due to usage, time, changes in technology, etc. Generally, depreciation is deducted from the original values in order to show the net book value of fixed assets.

The depreciation is calculated by an annual amortisation amount that assesses the annual decrease of the asset value in the elapsed year. The difference between the initial value of the asset and depreciation makes it possible to estimate the residual value of the asset concerned. We assume that the asset capital value on time $t$ is equal to the residual value. The accounting depreciation indicates the economic obsolescence of the considered asset, but constitutes a source for self-budgeting for the asset owner at time $t$. From an accounting point of view, the amount of depreciation is considered as a non-cash charge, which can be reinvested to renew the pipe asset.

Because of the inflation and the importance of service life of the pipe asset, the total depreciation amount can represent up to $25 \%$ of the budgeting of a new pipe asset. The monitoring of residual value can thus help decision makers to keep pipes with high residual value in place until the investment is amortised. It is obvious that the water utility should maintain the pipe asset as long as possible and should not excavate those with high residual value for two reasons: (1) there is no market for excavated pipes, so even if the residual value is still high, the asset cannot be sold; and (2) the utility loses the capacity to amortise itself over its entire expected service life. The early renewal of the asset implies a loss of value for the water utility because it requires a new investment with higher value than the historical one. The capital residual value is time-dependent: it can be assessed at each time period $t$ by the function $V_{r j}(t)$. It depends on: (i) the historical or initial value of the pipe asset $V_{0 j}$ at the installation date $t_{0}$; and (ii) the duration of the expected service life $D_{\mathrm{j}}$ as recommended by the $P S A B$.

Before assessing the capital residual value, the asset accounting depreciation must be fitted. Several depreciation trends can be applied (linear, constant, increasing, decreasing). In practice, linear amortisation is the most frequently applied trend. It assumes that the annual depreciation rate is constant, which corresponds to a constant annual depreciation amount. The annual depreciation rate $A R_{\mathrm{j}}$ for pipe $j$ is given by the following equation:

$$
A R_{j}=\frac{V_{0 j}}{D_{j}}
$$

The residual value decreases over time until it reaches zero at the end of the accounting life. The residual value $V_{\mathrm{rj}}(\mathrm{t})$ of a pipe $j$ at time $t$ is computed from the new value in new condition $V_{n j}$ or the historical value of the pipe, and the accounting lifetime $D_{j}$. The calculation is as follows: 
$V_{r j}(t)=A R_{j} \cdot\left(D_{j}-A g e_{j}(t)\right)$

where the age of the asset $j$ at time $t$ is obtained by:

$\operatorname{Age}_{j}(t)=t-t_{0}$

where $t_{0}$ is the installation date.

Equation (2) becomes:

$$
V_{r j}(t)=-A R_{j} . t+A R_{j} .\left(D_{j}+t_{0}\right)
$$

The capital residual value function is obtained according to a linear equation with a negative slope of $\left(-A R_{j}\right)$ and constant of $\left(A R_{\mathrm{j}} .\left(D_{j}+t_{0}\right)\right)$.

The residual value can be evaluated on a cohort of pipes by summing up the weighted values of individual pipes with a length $l j$, for $\mathrm{n}$ pipes. Because the capital value of the pipe is correlated to the pipe length, the residual value is obtained as follows:

$$
V_{r}(t)=\frac{\sum_{j=1}^{n} l_{j} \cdot V_{r j}(t)}{\sum_{j=1}^{n} l_{j}}
$$

Because of left-censuring of financial data, the historical value of assets installed decades ago is unknown. The lack of this information makes it difficult to estimate the annual depreciation rate $A R_{\mathrm{j}}$. To tackle this problem, the residual value at a given time can be measured by the relative value $V_{r}{ }_{r}(t)$ that expresses a percentage of the remaining value as follows:

$$
V_{r}^{\prime}(t)=\frac{V_{r j}(t)}{V_{0 j}}
$$

By substituting these equations for $V_{r j}(t)$ and $\mathrm{V}_{0 j}$, respectively, the following equation is obtained for calculating the relative residual:

$$
V_{r}^{\prime}(t)=\frac{D_{j}-\left(t-t_{0}\right)}{D_{j}}
$$

It can be observed that this equation depends on the installation date and the expected service life. The maximum value is equal to 1 when the asset is new, and decreases over time to 0 at the end of the asset lifetime. The residual value is therefore correlated to ageing. The purpose of recording depreciation is to show the decline of usefulness of an individual or a group of assets. The equations presented make it possible to estimate the residual accounting value in an interesting way for counterbalancing the lack of data concerning the installation value, which is rarely available. Beyond the assessment, this study aims at using the monitoring obtained to carry out a joint analysis 
of the capital and functional value of the pipe asset. This way of dealing with the problem is innovative since the deterioration of the function performed by the asset is not completely correlated to the capital depreciation or the physical or hydraulic capacity degradation, but is the combination of all of them. It can also be linked to specific factors such as caducity or obsolescence. The proposed approach also investigates the possibility of maintaining an old asset or an asset with low capital value in operation, particularly when the asset continues to deliver the needed service.

Many questions arise about these concepts of depreciation and deterioration because phenomena are simultaneous, time-dependent and concern different aspects of the asset. Concerning the decision process for pipe renewal, this study addresses how and when the pipe asset should be renewed in order to reach a trade-off situation that will ensure a low capital residual value and a high functional value. The figure below clearly illustrates the problem and raises the question of how the increase of knowledge about the deterioration and depreciation functions can help us to improve decision making for pipe renewal. The challenge is to help decision makers to use the analysis of asset value to enhance their decision-making process.

[Figure 1. near here]

\section{RELIABILITY ASSESSMENT AND SURVIVAL ANALYSIS APPROACHES: STATE OF THE ART AND POTENTIAL IMPROVEMENTS}

This section discusses the main approaches dedicated to the survival analysis used to deal with the problem of reliability assessment. The survival analysis applied for technical devices is generally based on statistical models adapted from the domain of biology and epidemiology. By analogy with the birth and death events of individuals (or species), a pipe asset is considered to be similar to individuals within a population (in our case, the pipe network), which is damaged by unexpected events (failure, breakage, interruption) assimilated to a death. In the survival analysis, the occurrence of an unexpected event on a pipe is considered to be a "death", and the repair of the pipe asset leads to the birth of a new individual that lives until the next event occurs.

Christodoulou (2011) defined survival analysis as a branch of statistics that addresses deterioration and failure over time by modelling the elapsed time between initial events and the next tracked event, from a population of observed objects (assets, individuals, components). Survival analysis is based on the analysis of data concerning event occurrence. These data are left-censured, which means that the observation of the asset did not start at the time of the installation. Another type of censuring concerns right-censored data, which means that the condition of the analysed asset is unknown after the observation date. This is the situation that mainly characterises the pipe asset, which is damaged by several events but that could operate if it is repaired. Three types of assets can be defined: (i) non-repairable assets, for which the function is interrupted when an unexpected event occurs (death); (ii) repairable assets, not right-censored, that correspond to the situation where the asset is faced with unexpected events but continues to operate until an observed end of life; and (iii) repairable assets, right-censored, that correspond to the situation where the asset faces unexpected events but continues to operate until an unobserved end of life. The first situation is largely addressed in the literature by the use of two types of survival analyses: parametric and nonparametric analyses.

\section{Parametric survival analysis}

Parametric survival analysis has been widely dealt with in the literature and is commonly based on the Weibull density probability function $f(t)$ to describe elapsed time between the occurrence of 
failures and ends of lives (Lee, 1992). Survival analysis is based on the calibration of the survival function $S(t)$ that estimates the likelihood that an asset will continue to function at least beyond a time $t$ where $\mathrm{T}$ is the time elapsed from the installation date or observation date and $h(t)$, the hazard function that indicates the intensity of failure occurrences where:

$$
S(t)=P(T \geq t)=1-\int_{T=0}^{t} f(u) d u
$$

The hazard function corresponds to the conditional probability to survive until time $t$ and fails at time $(t+\Delta t)$. The analytic expression is given by the equation below:

$$
h(t)={ }_{\Delta t} \varliminf_{0^{+}} \frac{P(t \leq T<t+\Delta t / T \geq t)}{\Delta t}=\frac{f(t)}{S(t)}
$$

\section{[Figure 2. near here]}

The second and third situation concerning data censuring and asset repair characteristics are partially addressed by the survival analysis. In spite of improvement through the use of exogenous and endogenous covariates, a better understanding of the structural deterioration processes such as those implemented on the Proportional Hazard Model (PHM) or Non-Homogeneous Poisson Model $(N H P M)$ makes it possible to improve the prediction of cumulative failures for the pipe asset. Statistical models were designed to predict events, but not necessarily for survival functions fitting.

\section{Non-parametric survival analysis}

The widest approach dedicated to investigating the duration of an individual's life based on population data is the Kaplan-Meier survival analysis method (Kaplan \& Meier, 1958). The method was initially applied in the medical domain but has been adapted for survival analysis in several domains. The object of the analysis can be individual, animal, equipment or any technical device. It is based on the following hypotheses: (i) each individual is tracked on an observation window where only one event can happen (failure, death). The method is mainly adapted for uncensored data or for right-censured data, which means that the individual is still in life beyond the end of observation; (ii) the method analyses the occurrence of events on a population of individuals, e.g., a population with decreasing cardinals; (iii) for technical devices, the method is applied for non-repairable equipment, and the occurrence of an event corresponds to the end of life of the device. The method is broadly implemented to measure how long it takes for any tracked event to occur, e.g., for a technical asset, the time until the end of service life or the time until failure occurs.

Based on the hypothesis that an asset is considered out of order (dead) when a failure occurs, the method counts the number of operating assets (individuals alive) and of those out of order (number of deaths) that occur over intervals of time or at time $t$. For each period of time, these data are computed to assess two survival probabilities: i) the conditional survival probability function and ii) the cumulative survival probability function.

The conditional survival probability function, $S_{c}(t)$ at time $t$, is the probability of surviving beyond a time $t$ based on the record of deaths $d(t)$ that corresponds to the total number of deaths that occurred (or out of order equipments) at time $t$ or over the time period $\mathrm{t}$, and $n(t)$ that corresponds to the 
number of individuals still alive in the population with respect to the constraint $d(t) \leq n(t)$. The ratio between $d(t)$ and $n(t)$ estimates the mortality probability or death probability at time $t$. $S_{c}(t)$ is obtained as follows:

$$
S_{c}(t)=1-\frac{d(t)}{n(t)}
$$

Equation (10) makes it possible to assess the cumulative survival function $S(t)$ at each time step t. It is obtained by the cumulative product of the conditional probabilities from the beginning of the observation window until time $t$ as follows:

$$
S(t)=\prod_{i=1}^{t}\left(1-\frac{d(i)}{n(i)}\right)
$$

The survival function curve plot is a concatenation of horizontal steps with constant magnitude over a time step until the next event occurs, implying a decline of magnitude. The curve forms a stairstep shape.

Since the survival function estimates the likelihood of an asset to still operate over a time $t$, it can be used to evaluate the residual physical functional value of an asset.

The popularity of the Kaplan-Meier method can be explained by its simplicity of implementation and the ease with which conditional probabilities can be assessed. It seems relevant in certain domains with respect to the method's hypothesis. The method is better adapted for non-repairable assets, where the asset is replaced by a new one when it fails.

In the case of pipe assets, the use of this method requires its adaptation, which implies violating its hypothesis. A pipe asset cannot be excavated completely when it fails for the first time; this is unrealistic and economically unfeasible. The first adaptation concerns the release of the constraint concerning the number of unwanted events, which becomes greater than one. A pipe asset will be excavated after a certain number of failures that make its structural condition fragile and affect its function. In that case, an individual will die, not when the first event occurs but over a threshold of failures that should be fitted. This situation is quite similar to the accelerated deterioration period highlighted by models dedicated to parametric survival analysis. It is also close to the concept of degradation states that is commonly used in the Markov chain process to define possible states of the analysed state. This approach seems more adapted to repairable assets.

In fact, (Saldanaha et al. 2001) considered that the distinction between repairable and nonrepairable systems (or components) is not clearly established by the reliability community. In reliability analysis, the use of the Markov chain approach has been used to perform the analysis of inspectable and repairable systems. The analysis of asset condition is based on the definition of deterioration states according to specific inspection diagnoses. The transition from one state to another is characterised by transition probabilities. The use of the Markov chain approach for buried water pipes is not relevant because of the difficulty to inspect pipes and to diagnose their states. The method seems more relevant for inspectable assets (Sharabah et al. 2006).

\section{INNOVATIVE APPROACH FOR THE FUNCTIONAL VALUE ASSESSMENT OF WATER PIPES}

The proposed approach for functional value assessment of the pipe asset is derived from the nonparametric survival function analysis applied for discrete variables. It is a low level approach that makes it possible to assess the function value of individual assets. The methodology developed is an 
adaptation of the Kaplan-Meier approach, Kaplan and Meier (1958). The proposed adaptation enables calibrating an interesting residual function for asset value based on both structural and hydraulic deterioration.

We assume that the functional value is composed of: (i) a structural functional value; and (ii) a hydraulic functional value. The structural functional value is a particular adaptation of the concept of survival function for repairable assets.

The functional value redefines the hypothesis of standard functional analysis by considering the pipe asset as an individual that can "die" several times. This hypothesis relaxes the hypothesis where the asset is removed (dies) when it breaks or fails, which can be true for non-repairable assets. In the case of the pipe asset, there is no theoretical limit to the number of repairs (or breaks) that leads to asset renewal. In reality, even if a pipe asset $j$ can be indefinitely repaired, the utility manager will decide to renew it after the cumulative number of failures goes beyond a certain threshold, designated $\alpha_{j}$. Another hypothesis concerns the non-censoring of failure observations (right-censoring) at the end of the observation window, which assumes that the pipe asset still operates and is not removed (does not die) at the end of the analysis, a situation that cannot be treated by parametric or non-parametric survival analysis. The current method is developed in the context of non-left-censured data, which means that the observation of the asset begins at the time of its installation. The occurrence of an unexpected event (failure, breakage, leaks) deteriorates the condition and harms the functionality at the same time. The instantaneous deterioration rate at time $t$ with number of incidents $n(t)$ observed for the asset pipe $j$ is calculated by $r_{\mathrm{j}}(t)$ as:

$$
r_{j}(t)=\frac{n(t)}{\alpha_{j}-\sum_{t=1}^{T} n(t-1)}
$$

For a repairable asset, it is obvious that a curative maintenance action partially or completely restores the structural condition. In that case, the deterioration rate is attenuated by the restoration rate, designated $\beta_{j}$ and comprised between 0 and 1 . The instantaneous deterioration rate is corrected as follows:

$$
r_{j}(t)=\left[\frac{n(t)}{\alpha_{j}-\sum_{t=1}^{T} n(t-1)}\right]\left[1-\beta_{j}\right]
$$

The structural deterioration rate allows us to calculate the instantaneous structural functional value $f v_{\mathrm{s}, \mathrm{j}}(t)$ for the pipe $j$ at time $t$ by:

$$
f v_{s, j}(t)=1-r_{j}(t)
$$

When the pipe asset is observed over the observation window $[0, T]$, the cumulative structural functional value $F V_{s, j}(\mathrm{t})$ is given by the following equation:

$$
F V_{s, j}(T)=\prod_{t=0}^{T} f v_{s, j}(t)
$$


The following section presents how the hydraulic deterioration of the pipe asset can be measured over time. It is assumed that it is correlated to the change in pipe roughness over time, which has an impact on the hydraulic capacity of the pipe and decreases its hydraulic function.

Colebrook and White (1937) were among the first to address the evolution of roughness over time. Hudson (1966) investigated the variation of $\mathrm{C}^{\mathrm{HW}}$ over time for several water networks in the USA. Sharp and Walski (1988) proposed an equation that described the effect of ageing on the $\mathrm{C}^{\mathrm{HW}}$. The equation is as follows:

$$
C^{H W}{ }_{j}(t)=18-37.2 \operatorname{Ln}\left(\frac{e_{o j}+a_{j}\left(t+g_{j}\right)}{D_{j}}\right)
$$

where $e_{\mathrm{oj}}$ : the initial roughness value of pipe $\mathrm{j}$ when it is new

$$
\begin{aligned}
& a_{\mathrm{j}} \text { : roughness growth }(f t / y r) \text { in pipe } \mathrm{j} \\
& D_{\mathrm{j}}: \text { diameter of the pipe } j(f t) \\
& g_{\mathrm{j}}: \text { age of the pipe } \mathrm{j} \text { at the present time (analysis period) } \\
& t \text { : elapsed time from the present to the future }
\end{aligned}
$$

Based on previous elements, the hydraulic functional value for pipe $j$ at time $t$ can be calculated by the ratio between Hazen-William coefficients as follows:

$$
F V_{h, j}(t)=\frac{C^{H W}(t)}{C^{H W}(0)}
$$

The proposed equation does not deal with the decrease of the pipe section due to potential incrustation over time. This aspect should be addressed in a future study. Beyond the possible improvements of proposed assessment functions, it appears that the evaluation of the functional value should be deduced from the structural and hydraulic functional values simultaneously. Many analytic functions can be tested. They must ensure that the functional value is low if the structural or hydraulic functional value is also low. Let's consider a threshold $l_{v}$ for the hydraulic and functional value below which the pipe is considered as candidate for renewal. Based on this observation, a possible analytic function to assess the functional value is defined by the equation 18.

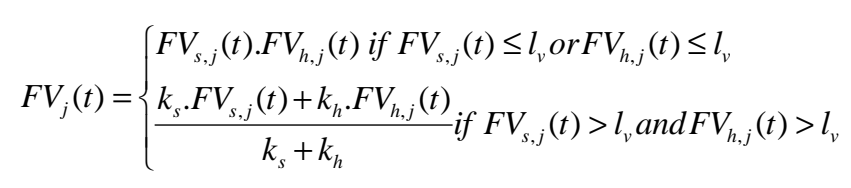

Where $k_{s}$ is the weight indicative of the importance of the structural function value, and $k_{h}$ indicates the importance of the hydraulic functional value. The weight values can be elicited from the decision maker's opinion. 
The interpretation of the calculated values depends on the preferences of the decision maker and how the deterioration types are sorted. Beyond this aspect, what should be relevant in the analysis is the comparison between hydraulic and physical deterioration, on the one hand, and the residual capital value, on the other. What will be interesting for the water utility is to maintain the installed pipe asset that has been amortised, with low capital residual value and high or medium physical or hydraulic value. In order to make the interpretation of the value obtained easier, the interval of values between 0 to 1 is split into three intervals, each defining a category as follows: (i) "high value" for values above 0.66; (ii) "medium value" for values between 0.66 and 0.33 ; and (iii) "low value", for values under $l_{v}=0.33$. In order to help the decision maker to interpret the obtained value, the following table indicates the situation where the pipe asset should not be considered as a candidate for renewal; all other cases require possible replacement. The table 1 provides an alternative way for water pipes prioritisation by analysing simultaneously obtained residual values and without using a specific analytic function to assess the functional value.

[Table.1. near here ]

\section{CASE STUDY}

The methodology was applied to the same case study treated in Tlili and Nafi (2012). The network is part of a real municipal network consisting of 147 cast iron pipes, with a diameter ranging from 150 to $250 \mathrm{~mm}$ and installed from 1951 to 1960 . The pipe networks have been monitored since their installation date, making the history of annual breakage available until 2003 (last observation year). It constitutes an observation window with right-censored data. The total length of the network is approximately $23 \mathrm{~km}$. Two types of data are available: (i) the breakage events over the observation window for each pipe; and (ii) the value of $\mathrm{C}^{\mathrm{HW}}$ at the installation date and for the year 1997 (values had been randomly generated). The implementation of the method is detailed in three sections. The first section presents its application at the pipe level in order to: (i) assess the hydraulic, physical and capital residual value; (ii) understand the evolution of each value and how it can be interpreted. The second section addresses the assessment of functional values over the whole network and how the results obtained could be used in the decision-making process. The last section shows how criteria based on the concept of functional value can be used for a multi-criteria decision-aid approach. Three innovative criteria (the structural functional value, the hydraulic functional value and the capital value) are implemented according to a Normalized and Homogenous Weighted Sum (NHWS) and compared to the result obtained in Tlili and Nafi (2012).

\section{Individual pipe asset value}

The method can be implemented at the pipe level in order to evaluate the decrease in asset value over the observation window. Figure 3 shows the decrease of asset values on pipe $\mathrm{N}^{\circ} 3092$, installed in 1955, with a length of $339 \mathrm{~m}$ and damaged by 21 breaks. For accounting purposes, an expected service life of $D_{3092}=70$ years was chosen. It corresponds to the highest value recommended by most public accounting boards for pipe assets. This theoretical duration makes it possible to estimate the capital residual function at each time step, even if the historical value of the pipe is unknown. This is made possible by using Equation 4.

Concerning the functional value, the tolerated number of breaks that defines the threshold for pipe end of life $\left(\alpha_{3092}\right)$ is equal to 25 breaks. The restoration rate defined by $\beta$ is fixed at $25 \%$. Both parameters were defined according to an elicitation process with the water utility decision maker. The parameter values are considered similar for the entire pipe network.

Various decline trends can be observed. The decreases in capital, hydraulic and physical values are completely different. The physical deterioration appears to be faster than the capital and the 
hydraulic deterioration. At the end of the observation window, the relative residual capital value can be estimated according to Equation 7, where $V^{\prime}(t=2003)=0.31$. The structural functional value $F V_{s, 3092}(\mathrm{t}=2003)=0.26$ and the hydraulic value $F V_{h, 3092}=0.85$. It is clear that at 48 years of age, pipe asset $\mathrm{N}^{\circ} 3092$ is still in good condition from the hydraulic point of view, but has physically deteriorated as shown by the low structural value. Both the structural and capital residual values are low. Consideration of the pipe asset as a candidate for renewal depends on the weight of the type of deterioration in the decision process. If we focus on the hydraulic deterioration, the pipe can be considered to be in good condition, in which case it should not be selected for renewal, but according to its capital and physical deterioration, it should be removed because its value declines and converges to 0 . In this case, the pipe becomes a candidate for renewal with a time to be candidate for renewal, TCR $=48$ years. The analysis of Fig. 3 indicates that the proposed methodology makes it possible to monitor the decrease of value depending on three types of deterioration. The interpretation of results depends on the priorities and preferences of the decision maker. In the event of the same preference, weights are similar and equal to $1\left(k_{s}=k_{h}=1\right)$, and the functional value of pipe $\mathrm{N}^{\circ} 3092$ can be calculated by the equation 18 as $F V_{3092}(t=2003)=0.22$ with $l_{v}=0.33$.

\section{[ Figure 3. near here]}

It is essential to plot the three functions representing each type of residual value in the same graph. It makes it possible to compare and diagnose the pipe asset based on several asset values in the same time. The calculation of an average value by considering a functional value leads to a decrease in knowledge with regard to the asset condition. The analysis of several residual values simultaneously offers more flexibility and helps the decision maker to diagnose the condition of the asset from various point of view which leads to adapt the decision according to his priorities. The following section focuses on the sensitivity of the pipe selection process to the value of the parameters $\alpha$ and $\beta$. They are inferred on the basis of the utility manager's opinion. The values of these parameters are ad hoc and depend on each water utility context.

\section{Sensitivity analysis of the residual structural value}

The evaluation of the structural deterioration depends on two parameters: $\alpha$ and $\beta$. These parameters are fitted by the decision makers based on their knowledge of the network and their preference for pipe asset prioritisation criteria (pipe location, closeness of other buried infrastructure works, concerned consumers). It is clear that the parameter values will influence the pipe selected for renewal. To tackle this situation, a sensitivity analysis was carried out by testing several possible values for the parameters. First, brand ranges of values for $\alpha$ ranging from 5 to 40 were tested. The variation of the value has a strong impact on the residual structural value that oscillates between 0 and 0.63 . When the value of $\alpha$ is low, the decrease of the residual value is rapid because the pipe is considered to be vulnerable and critical as a result of the number of breaks or failures. In contrast, this value decreases slowly when the threshold of the acceptable number of events is higher. This type of analysis should be carried out at the pipe level or the level of the cohort of similar pipes in order to help decision makers to fit a compromise value for $\alpha$ according to the context of the water utility and their preferences. Another way to fit the $\alpha$ parameter value is based on the search for the optimal number of breaks that minimise the discounted total cost of pipe (considering replacement and maintenance) at the date of simulation. This can offer a mitigation solution that is exclusively based on the economic dimension. Improvements have to be made in future studies in order to more effectively fit the $\alpha$ parameter value.

[Figure 4. near here] 
[Figure 5. near here].

The variation of the structural value according to the restoration rate $\beta$ oscillates between 0.19 and 1. It depends on the capacity of the impact of the curative maintenance on the pipe condition. Two extreme situations can be observed: 1 ) when $\beta$ is equal to 0 , it means that maintenance does not restore the previous level of the asset condition. Therefore, in this situation, the structural residual value decreases to its lowest value of approximately $0.19 ; 2$ ) under the hypothesis that maintenance makes it possible to restore the entire condition, the residual value is always equal to 1 . Both situations are obviously unrealistic but allow the decision maker to fit the value of $\beta$ according to values comparison to the extreme cases. As for the calibration of the $\alpha$ value, the same type of analysis is recommended at the pipe level or the level of the cohort of similar pipes to fit the $\beta$ value. The value of $\beta$ seems to be time-dependent because the effect of the curative maintenance is not the same over time and the restoration rate could decrease in the case of ageing assets.

The sensitivity analysis highlights the importance of the fit of parameters $\alpha$ and $\beta$ and how they can influence the decrease of the structural residual value and the TCR. The calibration process is therefore important and difficult. It offers flexibility to the decision maker in terms of adapting values from pipe to pipe or group of pipes, depending on their importance in the water system operation. To match realistic conditions, the values of parameters should not be constant from pipe to pipe or from one time step to another. They should be adaptable and depend on specific covariates derived from pipes and their environmental characteristics, on the one hand, and the effect of maintenance and technological advances in over time, on the other. The calibration and selection of parameter values is the decision maker's prerogative.

\section{Analysis of residual value on the whole network}

In this section, a descriptive statistical analysis of hydraulic and capital residual values on the whole network is carried out for fixed values of $\alpha=25$ and $\beta=25 \%$. The analysis aims at diagnosing the whole trend of pipe asset conditions. It uses the obtained residual values at pipe level in order to describe the repartition of the obtained values into classes. For each class, frequency of value's apparition is assessed, which allows plotting the residual values distribution and cumulative curve on the whole network for the structural functional value in Fig.6.a, for the hydraulic functional value in Fig.6.b and for the capital residual value in Fig.6.c.

[ Figure 6a. near here]

[ Figure 6b. near here]

[ Figure 6c. near here] 
The analysis of the distribution of the structural functional value displayed by the Fig.6.a shows that more than $90 \%$ of the pipes have values over 0.7 . Concerning the hydraulic aspect, more than $90 \%$ of the pipes have a high hydraulic functional value comprised between 0.6 and 0.7 as shown by the Fig.6.b. This global trend indicates that even if the residual capital value tends to decrease to low values, the structural and hydraulic functional values are still high, which indicates that the network is still in good condition and is able to perform its function, even if $2 / 3$ of the capital value had been amortised. According to Fig. 6.c, more than $90 \%$ of the pipes have a medium capital residual value, comprised between 0.33 and 0.4 .

The proposed approach could encourage the decision maker to monitor the water network without renewing a large number of pipes, as was observed for this network where only three pipes (2\% of the total length) have a structural functional value under 0.33 . The analysis of structural, hydraulic and capital residual values offers an interesting insight into the current condition of the network. It makes it possible to globally assess its condition in order to adapt the renewal policy.

\section{Innovative criteria for multi-criteria analysis}

This section explores the use of criteria based on the concept of functional analysis as input for a multi-criteria analysis. A test was performed by implementing the Normalized and Harmonized Weighted Sum (NHWS) proposed in Tlili \& Nafi (2012) on the three criteria built according to the concept of asset value: functional, hydraulic and capital residual value. The results of pipe sorting based on the previous criteria were assessed by specific indicators (the number of avoided breaks, the number of previous breaks per replacement, the number of contiguities, the average replaced pipe length and the amount of savings due to mobilisation). This analysis was compared to the one carried out for the eight other criteria defined in our previous study (breakage rate, demand, hydraulic capacity, residual lifetime, component of loop or branch, material, diameter and clustering). The comparison was done over a time step defined as follows. The observation window was split into two intervals: a calibration period as of the time of installation and up to 1995, and a validation period between 1996 and 2003. It should be recalled that the solution recommended by the NHWS approach in Tlili and Nafi (2012) concerns ten pipes that represent approximately 5.61\% of the total network length. The same multi-criteria approach was implemented on the three criteria presented above. Pipes were sorted; a selection of those representing 5.60\% of the total network was done, corresponding to six pipes. The assessment of the two sortings obtained based on the two different sets of criteria was carried out according to the indicators defined above. The values are plotted on Fig. 7.

Analysis of the results shows that a small difference exists between the two applications. The main difference concerns the number of breaks avoided (calculated over the validation period), whereas the proposed approach shows that only seven breaks were avoided instead of nine. Another observation concerns the number of concerned pipes and their average length. The proposed approach focuses more on taller pipes with an average length that is twice as great. A significant difference concerns the previous cumulative breaks calculated for the calibration period and for the same percentage of the network length. The cumulative breaks are higher with 52 breaks for six pipes, compared to the solution obtained by the other set of eight criteria with 42 breaks for ten pipes. The criteria based on the asset value seem involving more the structural deterioration. Concerning savings due to mobilisation, the proposed approach does not result in significant savings because it does not ensure any gathering of work sites.

\section{[Figure 7. near here]}

The implementation of a multi-criteria approach based on criteria inspired by the asset value analysis leads to a pipe sorting with relevant assessment indicators. The tested sets of criteria could 
complete the multi-criteria approach by better considering the structural deterioration of pipes, which is not sufficiently taken into account since it is indicated by the indicator, "the cumulative number of previous breaks". The proposed criteria based on the asset value offers a trade-off between the number of criteria chosen, the complexity of criteria building and the relevance of pipe sorting obtained.

\section{SUMMARY AND CONCLUSION}

Like all other types of assets, the assessment of the condition of water distribution networks and their depreciation remains a rather complicated task. The prioritisation of pipe candidates for renewal depends on both the multi-criteria approach to be implemented and the decision criteria that can deal with technical, hydraulic, structural and economic dimensions. Criteria were weighted according to the decision-makers' opinions. The added value of the current research is the consideration of new dimensions in the prioritisation process for the renewal of drinking water pipes on the basis of the concept of functional value and asset depreciation. The aim of this study is to develop a conceptual framework around the functional value of an asset in order to mitigate its condition and help decision-makers to plan renewal policies in independent way with regard of other utilities constraints. The functional value was studied according to three different forms of degradation: structural, hydraulic and accounting. The proposed assessment functions for functional values should be improved by taking more covariates into consideration, as well as the issue of leftand right-censored data. The sensitivity analysis showed that results can be strongly influenced by the choice of the values of the $\alpha$ and $\beta$ parameters that represent the maximum number of incidents and the percentage of restoration due to maintenance actions.

Obviously, the choice of the values of these parameters depends mainly on managers' opinions and their degree of requirement or tolerance.

This paper focused on two main analyses using two types of data: i) historic of failures and ii) accounting data. The first part emphasized the evaluation of each of the three functional values: the structural value based on the rate of deterioration and the number of failures, the hydraulic functional value based on the instantaneous evaluation of the $C^{H-W}$ coefficient, and the accounting value based on a depreciation analysis approach.

The second part underlined the asset value at the level of individual pipes and at a larger scale by considering the whole network underlying their contribution to the decision-making process in terms of the prioritised pipe candidates for renewal. A sensitivity analysis was carried out to show the variability of the residual functional value and the shape of its depreciation curve by varying the values of the $\alpha$ and $\beta$ parameters. The sensitivity analysis helps the decision maker to better assess the global condition of pipe assets. Obviously and as already mentioned the asset value is also influenced by the percentage of recovery $\beta$ that indicates the impact of maintenance and repair actions. The measurement of these action impacts and the description of the relationship between the action and the recovery of the state are still misunderstood. These aspects should be addressed in a future study.

Another aspect to be emphasized here is that the calibration of $\alpha$ and $\beta$ parameters also depends on the hydraulic importance of a pipe. Even if the notion of hydraulic importance seems more 
interesting in the case of a branched network characterised by low resilience, a pipe which is upstream of a drinking water distribution system connected to a tank should have an elevated functional value, a low failure tolerance and a maximum recovery rate in order to be maintained.

The current study developed a conceptual framework for assessing the value of assets through the notion of functional value and the depreciation concept. This methodology confirms the hypothesis that aging assets could be maintained because they still perform their functions. The results are sensitive to changes in the parameter values that reflect the opinions and the requirements of decision makers and water utility managers. The present approach must be improved by carrying out a survey of more specific functions for assessing the asset value.

This methodology offers a good compromise between the analysis of the past and the future according to the occurrence of failures and the functional state of the asset. The results obtained are encouraging. They clearly highlight the relevance of considering both the physical and accounting depreciation in the ageing analysis of pipe assets. The proposed framework addresses an important challenge concerning the maintenance of ageing pipes in order to avoid unnecessary expenses and to limit the risk of not excavating a deteriorated pipe asset. This can help the water utility to better mitigate pipe renewal and provides them with an argument they can use with other utilities to avoid the excavation of pipes that are still in good physical condition. This could eventually be used to save money that could be used to renew more sensitive and deteriorated assets.

\section{REFERENCES}

Allehaux, D. and Tessier, P.,2002. Evaluation of the functional obsolescence of building services in European office buildings. Energy and Buildings : (34), $127-133$.

Australian Accounting Standard Board, AASB, 2013. AASB 116 Property, plant and equipment. Melbourne: Australian Government.

Australian Property Institute, API .,2008. Glossary of Property Terms, Australian Property Institute, PCA, REIV, Canberra.

Andreou, S.A., 1986. Predictive models for pipe break failures and their implications on maintenance planning strategies for deteriorating water distribution systems. Thesis (Ph.D). Department of Civil Engineering, Massachusetts Institute of Technology, USA.

Christodoulou, S., E., 2011. Water Network Assessment and Reliability Analysis by Use of Survival Analysis. Water Resource Management, (25) 229-1238. DOI 10.1007/s11269-010-9679-8.

Canadian Institute of Chartered Accountants, CICA, 2007. Guide of accounting for and reporting tangible capital assets. City of Ottawa: Guidance of local Government and local Government Entities. 
Clark, R. M., Stafford, C. L., and Goodrich, J. A., 1982. "Water distribution systems: A spatial and cost evaluation." J. Water Resour. Plng. and Mgmt. Div., 108(3), 243-256.

Colebrook C.F., White C.M., 1937a. Experiments with Fluid Friction in Roughened Pipes, Proceedings of the Royal Society of London, vol. 161,. 367-381.

Colebrook C.F., White C.M., 1937b. The reduction of carrying capacity of pipes with age, Proceedings of the Institution of Civil Engineers, London, vol. 7, pp. 99.

Constantine, A. G., Darroch, J. N., 1993. In S. Osaki, D. N. P. Murthy (Eds), Pipeline reliability: Stochastic models in engineering technology and management. Singapore: World Scientific.

Constantine, A. G., Darroch, J.N., and Miller, R. ,1996. Predicting underground pipe failure. Australian Water Works Association.

Cox,D.R, 1972. Regression models and life tables. Journal of Royal Statistic Society, 34(B) 187-22.

Direction Générale des Collectivités Locales, DGCL, 2004. La comptabilité M49 des services d'eau et d'assainissement. Paris : Ministère de l'intérieur, de la sécurité intérieure et des libertés locales.

Eisenbeis P., 1994. Modélisation statistique de la prévision des défaillances sur les conduites d'eau potable. Thesis (Ph.D). Louis-Pasteur university, Strasbourg, France.

Financial Reporting Standards, FRS, 1999. FRS 15 Tangible Fixed Assets. London: Accounting Standards Board.

Gómez, J.F., González, V.,Barberá,L. and Crespo., A., 2012. Functional and economic obsolescence of assets in network utilities according to different environmental factors. Advances in Safety, Reliability and Risk Management:.861-868.

Halhal, D., Walters, G. A., Ouzar, D. \& Savic, D. A. ,1997. Water network rehabilitation with a structured messy genetic algorithm. J. Water Resour. Plann. Manage. 123(3), 137-146.

Herz,R. K., 1996. Ageing process and rehabilitation needs of drinking water distribution networks. Journal of Water SRT-Aqua, 45 (5), 221-231.

Hudson, W. D., 1966Studies of Distribution System Capacity in Seven Cities. J. AWWA, Vol. 58, No. 2.

Hudson, W. D., 1966. Loss of Water Main Capacity. J. Southeastern Sec. AWWA, Vol. 30, , p. 44.

International Financial Reporting Standards, IFRS, 2012. IAS 16 Property, plant and Equipment. London: IFRS.

Kaplan, E.L and Meier, P., 1958. Nonparametric estimation from incomplete observations. Journal of the American Statistical Association, 282, (53) 457-481.

Kleiner, Y. and Rajani, B. B.,2001. Comprehensive review of structural deterioration of water mains: statistical models. Urban Water, 3 (3), 131-150.

Le Gauffre P., and Haidar H., 2008. Assessing the benefits of rehabilitation programmes defined with the CARE-W decision support system. Water Asset Management International 4 (1) 15-18.

Le Gauffre, P., Haidar, H., Baur, R., Poinard, D., and Schiatti, L.K., 2004. A multicriteria decision support tool for annual rehabilitation programmes of water networks. In Proceedings of the 4th International Conference on Decision Making in Urban and Civil Engineering Organization, Porto, Portugal, 28-30 October 2004. [CD-ROM].

Lee, E.T.,1992. Statistical Methods for Survival data Analysis. Wiley Eds.

Le Gat, Y., 1998. Etude statistique des défaillances des canalisations du résau d'irrigation de la société du canal de Provence. Cemagref, Bordeaux, France.

Le Gat, Y., 1999. Forecasting Pipe Failures in Drinking Water Network Using Stochastic Processes Models - 
Respective Relevance of Renewal and Poisson Processes. In: Proceedings of the 13th EJSW, 8 September - 12 September, Dresden University of Technology. ISBN: 3-86005-238-1

Möderl, M., and Rauch, W., 2011. Spatial Distributed Risk Assessment for Urban Water Infrastructure.In: Clark, Robert M.; Hakim, Simon; Ostfeld, Avi (Eds.), Handbook of Water and Wastewater Systems Protection. New York, Springer, ISBN 978-1-4614-0188-9, pp. 119 - 134.

Nafi A., and Kleiner, Y., 2010. Scheduling renewal of water pipes while considering adjacency of infrastructure works and economics of scale. ASCE Journal of Water Resources Planning and Management, 136, (5), 519-603, October 01.

Nafi A., and Werey C., 2009. Modèles d'aide à la décision et modèles de prévision de défaillances : Etat de l'art et enseignements méthodologiques. Research report. Strasbourg. France. 56 p. (Models of decision support and models for failure prediction: State of the art and methodological lessons. Research report. Strasbourg. France. 56 ).

Nafi A., and Werey, C., 2010. Aide à la décision multicritère : Introduction aux méthodes d'analyse multicritère de type ELECTRE. Ecole Nationale de Génie de l'eau et de l'environnement de Strasbourg. France. (Multicriteria decision support: Introduction to methods of multicriteria analysis, ELECTRE. National School of Engineering in Water and Environment of Strasbourg. France).

Marks, D. H., et al. (1985). Predicting urban water distribution maintenance strategies: a case study of New Haven, Connecticut. Report to the Environmental Protection Agency by the Department of Civil Engineering, Massachusetts Institute of Technology, Cambridge, Mass

Ostfeld., A., Kogan., D and Shamir., U, 2001. Reliability simulation of water distribution systems - single and multiquality. Urban Water 4 (2002) 53-61.

Rajani, B., and Kleiner, Y., _2001_. Comprehensive review of structural deterioration of water mains: Physically based models. Urban Water, $3($ ), $15 \overline{1}-164$.

Rajani, B., and Kleiner, Y._2002_. Towards pro-active rehabilitation planning of water supply systems. International Conference on Computer Rehabilitation of Water Networks CARE-W, Dresden, Germany, Nov, 29-38.

Røstum, J., 2000. Statistical modelling of pipe failures in water networks. Thesis (PhD). Norwegian University of Science and Technology, Trondheim, Norway. ISBN 82-7984-033-8.

Saldanha, P.L.C., De Simone, E.,A. and Frutuoso e Melo, P.,F.,2001. An application of non-homogeneous Poisson point processes to the reliability analysis of service water pumps. Nuclear Engineering and Design : (210), 125- 133.

Shamir, U., and Howard, C.D.D., 1979. An analytic approach to scheduling pipes replacement. Journal of the American Water Works Association, 71(5): 248-258.

Sharabah, A, Setunge, S \& Zeephongsekul, P., 2006. Use of Markov chain for deterioration modelling and risk management of infrastructure assets. Proceedings of the International Conference on Information and Automation, Colombo, Sri Lanka, 384-389.

Sharp, W. W., and Walski, T. M., 1988. Predicting internal roughness in water mains. J. Am. Water Works Assoc., $80(11), 34-40$.

Tlili, Y. and Nafi, A., 2012. A practical decision scheme for the prioritization of water pipe replacement. Water Science \& Technology: Water Supply, 12 (6), 895-917. doi:10.2166/ws.2012.068.

Todini, E., 2000. Looped water distribution networks design using a resilience index based heuristic approach. Urban Water, 2 (3), 115-122

Walski, T.M and Pelliccia, A., 1982. Economic analysis of water main breaks. Journal of AWWA, 74 (3). 140-147. 
Figure 1. Pipe asset deterioration and depreciation.

Figure 2. Survival analysis function shape

Figure 3. The functional, hydraulic and capital residual values over time for pipe $\mathrm{N}^{\circ} 3092$.

Figure 4. The variation of the structural residual value according to $\alpha$.

Figure 5. The variation of structural residual value according to $\beta$.

Figure 6a. The distribution of the residual value over the whole network: case of structural functional value

Figure 6b. The distribution of the residual value over the whole network: case of hydraulic functional value

Figure $6 \mathrm{c}$. The distribution of the residual value over the whole network: case of capital value

Figure 7. Assessment indicators for renewal policies.

Table.1. Value interpretation for decision

\begin{tabular}{|l|l|l|l|l|l|l|l|l|l|l|}
\hline \multirow{2}{*}{ Decision } & \multicolumn{3}{|l|}{ Structural value } & \multicolumn{3}{l|}{ Hydraulic value } & \multicolumn{2}{l|}{$\begin{array}{l}\text { Relative residual capital } \\
\text { value }\end{array}$} \\
\hline $\begin{array}{l}\text { Pipe should } \\
\text { be } \\
\text { maintained }\end{array}$ & Low & Medium & High & Low & Medium & High & Low & Medium & High \\
\cline { 2 - 11 } & & $\mathrm{X}$ & $\mathrm{X}$ & & $\mathrm{X}$ & $\mathrm{X}$ & $\mathrm{X}$ & & \\
\cline { 2 - 11 } & & $\mathrm{X}$ & $\mathrm{X}$ & & $\mathrm{X}$ & $\mathrm{X}$ & & $\mathrm{X}$ & \\
\cline { 2 - 11 } & & $\mathrm{X}$ & $\mathrm{X}$ & & $\mathrm{X}$ & $\mathrm{X}$ & & & $\mathrm{X}$ \\
\hline
\end{tabular}

